\title{
Experiências de aprendizes de inglês da educação superior com o Kahoot: a colaboração e a multimodalidade em jogo
}

\author{
Fernanda Franco Tiraboschi ${ }^{1}$ \\ Laryssa Paulino de Queiroz Sousa ${ }^{2}$ \\ Francisco José Quaresma de Figueiredo ${ }^{3}$ \\ Neuda Alves do Lago ${ }^{4}$
}

Programa de Pós-Graduação em Letras e Linguística, Universidade Federal de Goiás, Goiânia, GO, Brasil

Resumo: Neste texto, relatamos uma experiência de ensino-aprendizagem de língua inglesa com o uso do Kahoot, numa perspectiva que alia a pedagogia dos multiletramentos (COPE; KALANTZIS, 2000, 2009; KRESS, 2010; LEMKE, 2010; PAESANI; ALLEN; DUPUY, 2016; ROJO, 2012) à aprendizagem colaborativa (DONATO; MCCORMICK, 1994; FIGUEIREDO, 2005, 2006, 2015, 2019; LANTOLF; APPEL, 1994). Tal investigação se justifica pelo fato de que é preciso saber lidar com as constantes mudanças contemporâneas relativas às práticas multiculturais suscitadas pela globalização, bem como às linguagens multimodais proporcionadas pelos avanços tecnológicos. Este estudo de caso foi realizado em um contexto de educação superior com sete participantes que estavam cursando Letras-Inglês no primeiro semestre de 2018. Os dados apresentados provêm da descrição da atividade, das respostas dos participantes a questionários e das narrativas de aprendizagem escritas por eles. Como resultados destacam-se, principalmente, a promoção de práticas de leitura de textos multimodais e o desenvolvimento do diálogo colaborativo.

Palavras-chave: Multiletramentos; Colaboração; Kahoot; Aprendizagem de línguas.

Title: Experiences of English learners in higher education with Kahoot: in-game collaboration and multimodality

\footnotetext{
${ }^{1}$ Doutoranda do Programa de Pós-graduação em Letras e Linguística da Universidade Federal de Goiás. Professora de Língua Inglesa da Faculdade Alfredo Nasser. Orcid: http://orcid.org/0000-0002-3812-7918.

E-mail: nandafranco87@yahoo.com.br

${ }^{2}$ Doutoranda do Programa de Pós-graduação em Letras e Linguística da Universidade Federal de Goiás. Bolsista Capes. Orcid: http://orcid.org/0000-0001-6790-5611.

E-mail: laryssa.paulino1@gmail.com

${ }^{3}$ Doutor e Pós-doutor em Linguística Aplicada pela Universidade Federal de Minas Gerais. Professor Titular do Programa de Pós-graduação em Letras e Linguística e Diretor de Relações Internacionais da Universidade Federal de Goiás. Orcid: http://orcid.org/0000-0002-5936-1578.

E-mail: fquaresma@terra.com.br

${ }^{4}$ Doutora em Letras e Linguística pela Universidade Federal de Goiás. Professora Adjunto II do Departamento de Línguas Estrangeiras e do Programa de Pós-graduação em Letras e Linguística da Universidade Federal de Goiás. Orcid: http://orcid.org/0000-0003-0887-9083.

E-mail: neudalago@hotmail.com
} 
Abstract: This paper reports on an English language teaching and learning experience with the use of Kahoot in a perspective that combines the pedagogy of multiliteracies (COPE; KALANTZIS, 2000, 2009; KRESS, 2010; LEMKE, 2010; PAESANI; ALLEN; DUPUY, 2016; ROJO, 2012) with collaborative learning (DONATO; MCCORMICK, 1994; FIGUEIREDO, 2005, 2006, 2015, 2019; LANTOLF; APPEL, 1994). This research is justified on the grounds that it is of paramount importance to learn how to deal with ongoing contemporary changes connected to the multicultural practices brought about by globalization as well as with the multimodal languages provided by technological advances. This case study was conducted in a higher education context, in Brazil, with seven students who took English as a major in the first semester of 2018. The data generated come from the description of the activity done, the students' responses to a questionnaire, and the students' learning narratives. Among the findings, we highlight principally the promotion of multimodal text reading practices and the development of collaborative dialogues.

Keywords: Multiliteracies; Collaboration; Kahoot; Language learning.

\section{Considerações iniciais}

Saber lidar com as mudanças recentes relativas às práticas multiculturais suscitadas pela globalização, bem como às linguagens multimodais decorrentes dos avanços tecnológicos, tornou-se imperativo na vida contemporânea. Para tanto, Rojo (2009) advoga em favor da inserção das práticas de multiletramentos no contexto escolar. Segundo a autora, "[é] importante também hoje abordar as diversas mídias e suportes em que os textos circulam, já que há tempos o texto impresso e o papel deixaram de ser a principal fonte de informação e formação" (ROJO, 2009, p. 119). Nessa direção, ser letrado implica saber lidar com as situações de compreensão e produção de textos nas mais diversas modalidades e contextos (texto escrito, imagem, áudio, gestual etc.) (LANKSHEAR; SNYDER; GREEN, 2000; ROJO, 2009). ROJO (2012) ainda destaca o caráter interativo-colaborativo dos textos multissemióticos e multimodais, de modo que nos chama a atenção para o fato de que a pedagogia dos multiletramentos aponta para um paradigma de aprendizagem colaborativa (DONATO; MCCORMICK, 1994; FIGUEIREDO, 2005, 2006, 2015, 2019; LANTOLF; APPEL, 1994).

Ao considerar que o contexto de educação superior consiste na entidade formadora dos profissionais que atuarão na instituição escolar, torna-se fundamental não só uma reflexão teórico-metodológica acerca da pedagogia dos multiletramentos nos cursos de formação de professores, mas também a prática de atividades que possibilitem os multiletramentos dos professores aprendizes, uma vez que esses tendem a adotar as práticas pedagógicas já vivenciadas (FREEMAN; JOHNSON, 1998; NÓVOA, 2015).

Nóvoa (2015) argumenta que a articulação da prática à teoria é necessária desde a formação inicial dos professores. Para o autor, tal articulação é indispensável na transformação do processo de ensinar e de aprender nas escolas. Desse modo, se tomarmos o conceito de formação de professores como o processo de aprendizagem para ensinar 
(FREEMAN; JOHNSON, 1998), os cursos de formação, seja em estágio inicial ou continuado, precisam oportunizar práticas multiletradas em um viés colaborativo aos professores, para que eles possam também propor tais práticas a seus alunos. Conforme enfatizado por Warner e Dupuy (2018, p. 6), atualmente, as necessidades do campo de ensino e aprendizagem de línguas requerem estruturas mais integrativas que englobem o letramento, e isso "[...] tem sido reconhecido por acadêmicos, educadores e elaboradores de currículos" ${ }^{\prime \prime}$. Como consequência desse ajuste da didática do ensino de línguas ao mundo moderno, realçam os autores, "o interesse nas pedagogias de multiletramentos"6 (WARNER; DUPUY, 2018, p. 6) tem aumentado.

Dias (2012, p. 864) salienta que os recursos disponíveis pelas tecnologias digitais de informação e comunicação (TDICs) "[...] podem favorecer a formação do professor para as mudanças advindas da complexidade das inter-relações da era virtual". Contudo, é importante considerar, como nos alerta Warschauer (1996), que a inserção de recursos disponíveis pelas TDICs na aula de línguas por si só não garante a eficácia da aprendizagem; é preciso, entre outros fatores, levar em conta a abordagem de ensino-aprendizagem de línguas subjacente à atividade proposta.

Kessler e Hubbard (2017) salientam que o interesse na utilização das tecnologias das TDICs nos cursos de formação de professores tem passado por um aumento considerável, hodiernamente. Os professores necessitam, segundo os autores, compreender os princípios e desenvolver as habilidades necessárias para a implementação dessas ferramentas na sua didática de ensino. Reforçam o fato de que é necessário incluir o uso e a prática dessas tecnologias no currículo das licenciaturas porque, embora algumas pessoas possam aprender a sua utilização por meio de experimentação individual, "[...] para a maioria dos professores, uma maneira mais eficiente e efetiva é por meio do processo de educação formal"7 (KESSLER; HUBBARD, 2017, p. 278).

Diversos estudos, a partir de diferentes abordagens, têm demonstrado as vantagens resultantes da proposta de atividades com o uso da plataforma digital Kahoot na aprendizagem de línguas (LICORISH et al., 2017; MISSAGIA; GERRA, 2018; VALLIM; GOMES; FISCHER, 2017). Entretanto, não constatamos, nesses estudos, uma proposta de utilização da referida plataforma digital a partir de uma abordagem que integre os multiletramentos à aprendizagem colaborativa.

Esta pesquisa faz parte de um projeto maior intitulado "Estudo sobre os efeitos da colaboração no processo de ensino-aprendizagem de línguas em contextos presenciais e virtuais"8. A investigação em questão se organiza, especificamente, em torno de duas

\footnotetext{
${ }^{5}$ Original: "[...] has been recognized by scholars, educators, and curriculum designers".

${ }^{6}$ Original: "interest in the multiliteracies pedagogies".

7 Original: "[...] for most teachers a more efficient and effective way is through the formal education process".

${ }^{8}$ Número do Parecer: 2.363.676.
} 
perguntas centrais: a) quais aspectos de uma atividade colaborativa envolvendo o uso do Kahoot se relacionam aos princípios da pedagogia dos multiletramentos?; e, b) quais são as percepções dos aprendizes em relação aos efeitos da utilização dessa ferramenta digital nas aulas de inglês?

Para responder a essas perguntas, investigamos uma proposta de atividade voltada para aprendizes de Língua Inglesa I do Curso de Letras-Inglês de uma universidade privada a partir do uso do Kahoot numa perspectiva que alia a pedagogia dos multiletramentos à aprendizagem colaborativa. Ao considerar que o foco do estudo recai sobre a colaboração e a multimodalidade no contexto do Kahoot, buscamos, em um primeiro momento, refletir e descrever a atividade, ao tomar como base os gestos pedagógicos propostos por Cope e Kalantzis (2009) na perspectiva dos multiletramentos. Em seguida, procuramos compreender as percepções dos aprendizes no que se refere aos efeitos da inserção da plataforma digital Kahoot na aula de inglês.

Este artigo está dividido em cinco seções, além das considerações iniciais e finais. $\mathrm{Na}$ primeira seção, discutimos alguns pressupostos teóricos concernentes à aprendizagem colaborativa. Na segunda seção, expomos os princípios e conceitos subjacentes à pedagogia dos mutiletramentos, em um viés colaborativo, que se mostraram pertinentes a este estudo. $\mathrm{Na}$ terceira seção, explicitamos alguns aspectos metodológicos. Na quarta seção, tecemos reflexões acerca da atividade proposta, de maneira a identificar os aspectos que refletem os princípios dos multiletramentos. Na quinta seção, apresentamos as discussões referentes às percepções dos aprendizes atinentes aos efeitos da atividade com o Kahoot para a aprendizagem de inglês. Passemos à primeira seção.

\section{A colaboração na aprendizagem de línguas: alguns pressupostos teóricos}

A aprendizagem colaborativa fundamenta-se nos princípios da teoria sociocultural, a qual defende que a aprendizagem e o desenvolvimento cognitivo ocorrem através da interação mediada entre humanos e o meio socio-histórico e cultural no qual estamos inseridos. Desse modo, na aprendizagem colaborativa, os aprendizes se engajam em situações de interação, ajudando uns aos outros não só para a simples execução de uma determinada tarefa, mas, principalmente, para a coconstrução de conhecimentos durante o processo de realização de tal tarefa (DONATO; MCCORMICK, 1994; FIGUEIREDO, 2005, 2006, 2015, 2019; LANTOLF; APPEL, 1994).

Em sua teorização sobre o desenvolvimento cognitivo humano, Vygotsky (1998, p. 112) propõe a noção de Zona de Desenvolvimento Proximal (ZDP), definida como "a distância entre o nível de desenvolvimento real [...] e o nível de desenvolvimento potencial". Para o autor, o nível de desenvolvimento real refere-se à capacidade que o indivíduo tem de 
realizar uma determinada tarefa de forma independente. Por sua vez, o nível de desenvolvimento potencial diz respeito à possibilidade de realização de uma tarefa específica por um indivíduo a partir da ajuda de outra pessoa.

Outro conceito importante utilizado por pesquisadores da teoria sociocultural é o scaffolding ${ }^{9}$, que é compreendido como uma estrutura de apoio que possibilita a um indivíduo executar uma tarefa ou alcançar um objetivo de aprendizagem, o qual não conseguiria sozinho, por meio da ajuda de um adulto ou um par mais competente (DONATO; MCCORMICK, 1994; FIGUEIREDO, 2005, 2006, 2019; LANTOLF; APPEL, 1994; WOOD; BRUNER; ROSS, 1976). Contudo, Wertsch (1979, apud DONATO; MCCORMICK, 1994) ressalta que a noção de scaffolding pode ser mais abrangente, isto é, a ajuda não precisa necessariamente vir de um par mais competente, uma vez que, em um trabalho em grupo, cada membro pode contribuir com a execução de um objetivo em comum a partir de suas habilidades específicas, e que, por vezes, podem ser complementares.

Nessa mesma direção, Figueiredo (2006, p. 17), com base em outros autores (BENADO; TESTUT, 1991; NUNAN, 1992; NYIKOS; HASHIMOTO, 1997, entre outros), salienta que "a interação não ajuda apenas os alunos menos experientes; ela leva também os mais experientes a descobrir novas formas de aprender". O autor argumenta, ainda, que a utilização da teoria sociocultural em sala de aula provê um lócus de apoio recíproco entre os alunos, visto que "[...] quando trabalham juntos, eles têm a chance de discutir sobre suas próprias dúvidas, de compartilhar com os outros o seu conhecimento, de aprenderem juntos e de se ajudarem" (FIGUEIREDO, 2019, p. 109).

Dessa maneira, torna-se indispensável que aprendizes de línguas se engajem em situações de diálogo colaborativo, nas quais eles terão a chance de usar a língua, refletir sobre ela e coconstruir conhecimentos.

A noção de diálogo colaborativo foi proposta por Swain (2000), com o intuito de definir o diálogo no qual os participantes se engajam em soluções de problemas e na construção de conhecimento de modo colaborativo. Cabe destacar que, nas situações de interação dialógica, os fatores afetivos dos participantes também exercem influência de modo a promover ou inibir a aprendizagem de uma língua estrangeira. Nessa linha de raciocínio, Scarcella e Oxford (1992) ressaltam que as características individuais dos aprendizes podem atuar na ZDP. As autoras explicam que tais características podem incluir "motivação, autoestima, níveis de ansiedade, habilidade de assumir riscos, estilos e estratégias de aprendizagem"10 (SCARCELLA; OXFORD, 1992, p. 31).

Entre os fatores relativos à afetividade que podem prejudicar a aprendizagem de línguas, podemos destacar a introversão, entendida por Lago (2011, p. 21) como uma

\footnotetext{
${ }^{9}$ Conforme afirma Figueiredo (2019, p. 54), vários "[...] autores relacionam o conceito de scaffolding à teoria sociocultural de Vygotsky, especialmente ao conceito de ZDP, apesar de Vygotsky nunca ter usado o termo".

${ }^{10}$ Original: "motivation, self-esteem, anxiety level, risk-taking ability, learning styles, and learning strategies".
} 
característica de personalidade normalmente apresentada por pessoas que são "mais fechadas, quietas e tímidas". Aprendizes introvertidos, embora comumente descritos como tendo melhor desempenho no desenvolvimento da precisão gramatical do que os extrovertidos, podem apresentar dificuldades para se envolver de maneira ativa nas situações de interação dialógica (LAGO, 2011; SCARCELLA; OXFORD, 1992; WELLS, 1999). Por conseguinte, é possível que tal fato traga prejuízos significativos ao desenvolvimento da habilidade de produção oral na língua-alvo para aprendizes com essa característica. Todavia, acreditamos que o professor de línguas possa promover práticas de colaboração nas quais aprendizes de línguas, mesmo aqueles introvertidos, possam superar o desconforto a partir do apoio mútuo entre os interagentes e, assim, avançar no processo interacional da língua que estão aprendendo.

Cumpre lembrar que a aprendizagem colaborativa também favorece o desenvolvimento da autonomia do aprendiz. A esse respeito, Figueiredo (2006, p. 24) aponta que, em situações de atividades colaborativas, "os alunos têm a oportunidade de tornarem-se mais reflexivos e mais autônomos". Segundo o autor, as negociações entre os aprendizes os ajudam a passar de um estágio de regulação pelo outro para a autorregulação (FIGUEIREDO, 2006). É importante frisar ainda que, neste texto, consideramos a autonomia como a postura mais ativa do aprendiz na construção de seu próprio conhecimento, de forma que esse possa estabelecer os objetivos e tomar as decisões que melhor atendam às suas necessidades de aprendizagem (DICKINSON, 1994; FIGUEIREDO, 2006; LANTOLF; APPEL, 1994).

Convém lembrar ainda que o feedback corretivo, nas mais variadas formas, consiste em um fator fundamental no processo de aprendizagem de línguas (ELLIS, 2009). Os estudos sobre aprendizagem colaborativa têm demonstrado que o feedback corretivo fornecido pelos pares ou por membros de um grupo pode ser eficaz no sentido de que proporciona a negociação e a troca de papéis entre eles no tocante ao ato de ensinar e aprender (FIGUEIREDO, 2005, 2015, 2019; LIMA; COSTA, 2007).

Em relação às possibilidades de promover situações de aprendizagem colaborativa, Paiva (2001, p. 99) sinaliza que a internet pode se configurar como "um ambiente rico em oportunidades de construção de conhecimento", interação, troca de opiniões e participação em projetos colaborativos. De modo similar, Vurdien $(2019$, p. 273$)$ também ressalta os benefícios da comunicação mediada por computador (CMC), que se constitui num rico espaço para "[...] a interação social, oferecendo aos alunos oportunidades de usar a língua em um contexto autêntico para expressar suas impressões, transmitir informação, obter feedback instantâneo e avaliar a sua aprendizagem da língua-alvo"11. Seguindo essa linha de

\footnotetext{
${ }^{11}$ Original: "[...] social interaction, which provides students with opportunities to use language in an authentic context to express their views, convey information, obtain instantaneous feedback and assess their learning of the target language."
} 
pensamento, portanto, a ferramenta Kahoot pode funcionar como um recurso eficiente na aprendizagem de línguas, uma vez que consiste em uma plataforma digital on-line que promove a interação entre os usuários a partir da opção Team mode, de forma a contribuir para a negociação de significados e compartilhamento de saberes entre os interagentes (MISSAGIA; GUERRA, 2018; VALLIM; GOMES; FISCHER, 2017).

\section{A pedagogia dos multiletramentos sob o viés da aprendizagem colaborativa}

A pedagogia dos multiletramentos considera a diversidade cultural e de linguagens que constituem tanto a sala de aula como um modelo mais inclusivo de escola quanto as diversas práticas sociais que caracterizam a vida contemporânea. Em vista disso, essa perspectiva se mostra eficaz para a aprendizagem de línguas no cenário educacional atual, bem como para construir e relatar essa experiência de uma forma de multimodalidade, ou seja, o Kahoot na sala de aula de língua inglesa.

Tal abordagem se faz relevante, em primeiro lugar, porque coloca em foco a diversidade linguística e cultural existente tanto na sala de aula como fora dela, visto que, na sociedade contemporânea, líquida e global, faz-se necessário cada vez mais negociar diferenças.

Em segundo lugar, a pedagogia dos multiletramentos tem como cerne de suas preocupações a influência das novas tecnologias digitais, que se apresentam em linguagens multimodais, como a escrita, o áudio, as imagens, os gestos etc. (COPE; KLANTZIS, 2000). Nesse sentido, essa abordagem contribui não só para promover o conhecimento da estrutura linguística, mas também dos gêneros textuais impressos e digitais que a atualizam, e dos aspectos socio-históricos e culturais que incidem da e na linguagem.

A pedagogia dos multiletramentos teve início a partir de um movimento criado por pesquisadores conhecidos como o New London Group (NLG), no intuito de pensar formas de preparar o cidadão contemporâneo para lidar com o cenário de diversidade social, cultural e de diferentes modos de representação e construção de sentidos: linguístico, visual, espacial, gestual etc. (NEW LONDON GROUP, 1996). O prefixo multi, por conseguinte, tenta captar a ideia de multiplicidade inerente ao caráter multicultural e multimodal que perpassa as interações sociais estabelecidas atualmente. Adicionalmente, Rojo $(2012$, p. 12) salienta que o grupo sinalizava a importância de não só proporcionar os letramentos emergentes relativos às TDICs, mas também de considerar a diversidade cultural que caracteriza a sala de aula.

Vê-se que os multiletramentos apontam para uma educação linguística que promova situações de aprendizagem que engaje "os aprendizes no processo de interpretação, 
colaboração, solução de problemas e reflexão"12 (PAESANI; ALLEN; DUPUY, 2016, p. 12). Vale destacar ainda que os multiletramentos dos aprendizes, na contemporaneidade, são exigidos para a construção crítica de significados dos diferentes textos multimodais e multissemióticos que circulam nas diversas práticas sociais, bem como para a negociação das diferenças culturais, estejam elas imbricadas no microcontexto (lar, trabalho, escola etc.) ou no macrocontexto (como na internet e em conferências internacionais) (AGUILAR, 2007; KRESS, 2010; LEMKE, 2010; ROJO, 2012).

Importa salientar que a proposta da pedagogia dos multiletramentos para a educação linguística e, mais especificamente, para o ensino-aprendizagem de línguas estrangeiras, vai ao encontro dos princípios preconizados pela aprendizagem colaborativa. $A$ esse respeito, Lemke (2010) defende que o paradigma da aprendizagem interativa cada vez mais tem ganhado espaço em nossa sociedade. Rojo (2012, p. 27), por sua vez, argumenta que tal paradigma deve ser considerado não apenas como interativo, mas como colaborativo, visto que "[v]ivemos em um mundo em que se espera (empregadores, professores, cidadãos, dirigentes) que as pessoas saibam guiar suas próprias aprendizagens na direção do possível, [...] que tenham flexibilidade e consigam colaborar com urbanidade".

Em termos de procedimentos didáticos, Cope e Kalantzis (2009), numa perspectiva dos multiletramentos, propõem quatro atos didáticos, os quais eles chamam de gestos pedagógicos. Assim, para os autores, uma proposta pedagógica que tenha como foco propiciar práticas multiletradas deve contemplar os seguintes gestos pedagógicos: a) experienciamento (ou prática situada) que propõe práticas significativas de aprendizagem, de modo que considere o contexto sociocultural, bem como as necessidades e identidades do aluno; b) a conceitualização (ou instrução explícita), na qual os aprendizes se apropriam dos aspectos teóricos e conceituais a partir da mediação de um professor; c) a análise (ou enquadramento crítico) que se refere à promoção da capacidade reflexiva do aluno, no sentido de estabelecer relações entre os significados emergentes de textos multimodais e os contextos e propósitos sociais; e, finalmente, d) a aplicação (ou prática transformada) que está relacionada à capacidade do aprendiz no que tange à aplicação de novos conhecimentos e habilidades para se engajar em comunicações multimodais de maneiras criativas, levando em conta seus interesses, experiências e aspirações, de modo a transformar sua realidade.

Warner e Richardson (2017), em seu estudo sobre o ensino e a aprendizagem de alemão como segunda língua, apresentam ricas evidências de que a implementação de jogos digitais e outras mídias sociodigitais em cursos fundamentados nos multiletramentos pode se constituir numa abordagem muito útil para auxiliar professores e aprendizes a ampliar sua visão do processo de aprendizagem, dentro de um nexo mais amplo de práticas sociais. Entre as possibilidades de recursos digitais potencializadores de práticas multiletradas,

\footnotetext{
12 Original: "learners in the process of interpretation, collaboration, problem solving and reflection".
} 
elegemos o Kahoot porque veicula diferentes linguagens e textos multimodais, uma vez que é possível criar quizzes de múltipla escolha integrados a vídeos, imagens, diagramas etc. (VALLIM; GOMES; FISCHER, 2017).

\section{Aspectos metodológicos do estudo}

Esta investigação se caracteriza como uma pesquisa qualitativa e, mais precisamente, como um estudo de caso. De um modo genérico, tal metodologia se mostra eficiente para as investigações científicas no âmbito educacional, uma vez que possibilita uma abordagem que considera o dinamismo das situações, bem como a complexidade das dimensões dos atores envolvidos em tal contexto (NUNAN, 1992; PÉREZ SERRANO, 1998). O caso em estudo consiste na proposta de uma atividade, para aprendizes de língua inglesa, envolvendo a colaboração e textos multimodais/multissemióticos a partir da ferramenta digital Kahoot.

O contexto de pesquisa consiste em uma sala de aula de inglês de uma instituição privada de ensino superior. A atividade foi proposta para a turma do 10 período do curso de Letras-Inglês no primeiro semestre de 2018, pela professora do grupo, que é também a primeira autora deste artigo. O grupo era composto por vinte e cinco alunos e alguns deles já eram formados em outras áreas e exerciam suas profissões. Todos foram convidados a participar deste estudo, entretanto, apenas seis alunos escreveram suas narrativas de aprendizagem e responderam ao questionário. Desse modo, utilizaremos apenas os dados referentes a esses alunos. Optamos pela utilização da narrativa de aprendizagem e do questionário porque os participantes poderiam escrevê-los posteriormente, quando tivessem disponibilidade e enviá-los via e-mail. É importante frisar que a turma se caracterizava como heterogênea no que se refere ao conhecimento de língua, isto é, os aprendizes apresentavam níveis de inglês do básico ao avançado. A seguir, apresentamos um quadro com informações gerais sobre os participantes, geradas após a investigação:

Quadro 1 - Informações pessoais dos participantes

\begin{tabular}{cccc}
\hline Pseudônimos & Idade & Sexo & Grau de escolaridade \\
\hline Alice & 18 & feminino & Graduanda \\
Civínio & 18 & masculino & Graduando \\
Diane & 18 & feminino & Graduando \\
DD & 39 & feminino & Graduada em Direito \\
Harry & 18 & masculino & Graduando \\
Peter & 27 & masculino & Graduado em Publicidade e \\
& & & Especialista em Docência Universitária \\
\hline
\end{tabular}

Fonte: Elaborado pelos autores com base nas respostas ao questionário 
Neste artigo, contemplamos dois dados distintos: 1) a descrição da atividade realizada; e 2) as percepções dos aprendizes a partir de suas narrativas de aprendizagem (ver Apêndice A) e de suas respostas a um questionário (ver Apêndice B) aplicado após a realização da atividade.

\section{A atividade e os atos pedagógicos na perspectiva dos multiletramentos}

Conforme discutido anteriormente, Cope e Kalantzis (2009) propõem quatro atos pedagógicos ou gestos didáticos para o trabalho com o ensino-aprendizagem de línguas numa perspectiva dos multiletramentos. Conforme ressaltam Lenharo e Cristovão (2018, p. 382), "[s]eriam esses princípios que tornariam possível a estruturação de um trabalho utilizando-se de diferentes materialidades: sonora, digital, visual, escrita, gestual, entre outras". Ao tomar como base tal proposta, procederemos a uma descrição da atividade com o uso do Kahoot de forma a refletir sobre os aspectos que podem revelar os princípios dos multiletramentos, a saber, os gestos pedagógicos. É importante esclarecer que a atividade em estudo fez parte de um conjunto de quatro atividades continuadas no intuito de trabalhar de maneira progressiva o tema jobs and occupations. As atividades de 1 a 3 foram realizadas em uma mesma aula e a atividade 4 foi proposta como homework. Por isso, mostraremos de que modo cada atividade se articula aos atos didáticos e nos deteremos a uma descrição mais detalhada da atividade 3, que configura o foco de análise deste estudo. Observemos no quadro, a seguir, a classificação das atividades:

Quadro 2 - Classificação das atividades

\begin{tabular}{ccccc}
\hline Gestos pedagógicos & Experienciamento & Conceitualização & Análise & Aplicação \\
\hline \multirow{3}{*}{ Atividades } & Atividade 1: & Atividade 2: & Atividade 3: & Atividade 4: \\
& Questões em pares & Exposição de & Realização, em & Produção de \\
& sobre habilidades e & vocabulário e & grupo, do quiz com & vídeos em grupo. \\
& dificuldades. & exercícios individuais. & o uso do Kahoot. & \\
\hline
\end{tabular}

Fonte: Elaborado pelos autores com base na descrição das atividades.

A primeira atividade procurou valorizar os conhecimentos dos aprendizes e relacionar suas experiências ao conteúdo que seria proposto na sequência. Dessa forma, podemos situá-la no que Cope e Kalanzis (2009) chamam de experienciamento (ou prática situada), visto que foi proposta uma tarefa de warm-up a partir de um handout que contemplou a elaboração de questões, em pares, pelos próprios alunos sobre suas habilidades e dificuldades (strenghts and weaknesses) em relação à área de atuação profissional. 
Na segunda atividade, a conceitualização (ou instrução explícita) foi realizada a partir da exposição de vocabulário relativo a profissões e ocupações, bem como expressões e elementos gramaticais, comumente utilizados para falar sobre atividades atribuídas a determinadas funções, locais e departamentos no contexto do trabalho.

A plataforma Kahoot, como um recurso pedagógico, foi utilizada na terceira atividade, a qual se enquadra no ato didático denominado análise (ou enquadramento crítico). Essa etapa, por conseguinte, teve o objetivo de promover a reflexão dos aprendizes, no sentido de estabelecer relações entre os significados emergentes de textos multimodais de maneira colaborativa (COPE; KALANTZIS, 2009). Em linhas gerais, o Kahoot consiste em uma plataforma digital on-line e gratuita que permite a criação de jogos, tais como quizzes de múltipla escolha, aos quais podem ser acrescentados vídeos, imagens, diagramas, entre outros recursos que atribuem o caráter multimodal e multissemiótico a um texto. Tal plataforma pode ser acessada a partir de um smartphone ou de um computador. 0 professor/instrutor pode utilizar quizzes já disponíveis na plataforma ou criar os seus próprios.

Os aprendizes foram organizados em grupos e orientados sobre como utilizar a ferramenta. A professora acessou a plataforma via computador, usando sua conta, e a projetou no quadro através de um datashow. Em seguida, solicitou aos alunos que acessassem o website usando apenas um smartphone por grupo. Os alunos não precisavam ter uma conta na plataforma para acessá-la. Eles deveriam apenas digitar uma sequência numérica (PIN) que aparecia na tela projetada no quadro. Para ilustração, observemos a figura 1:

Figura 1 - Conexão via Kahoot

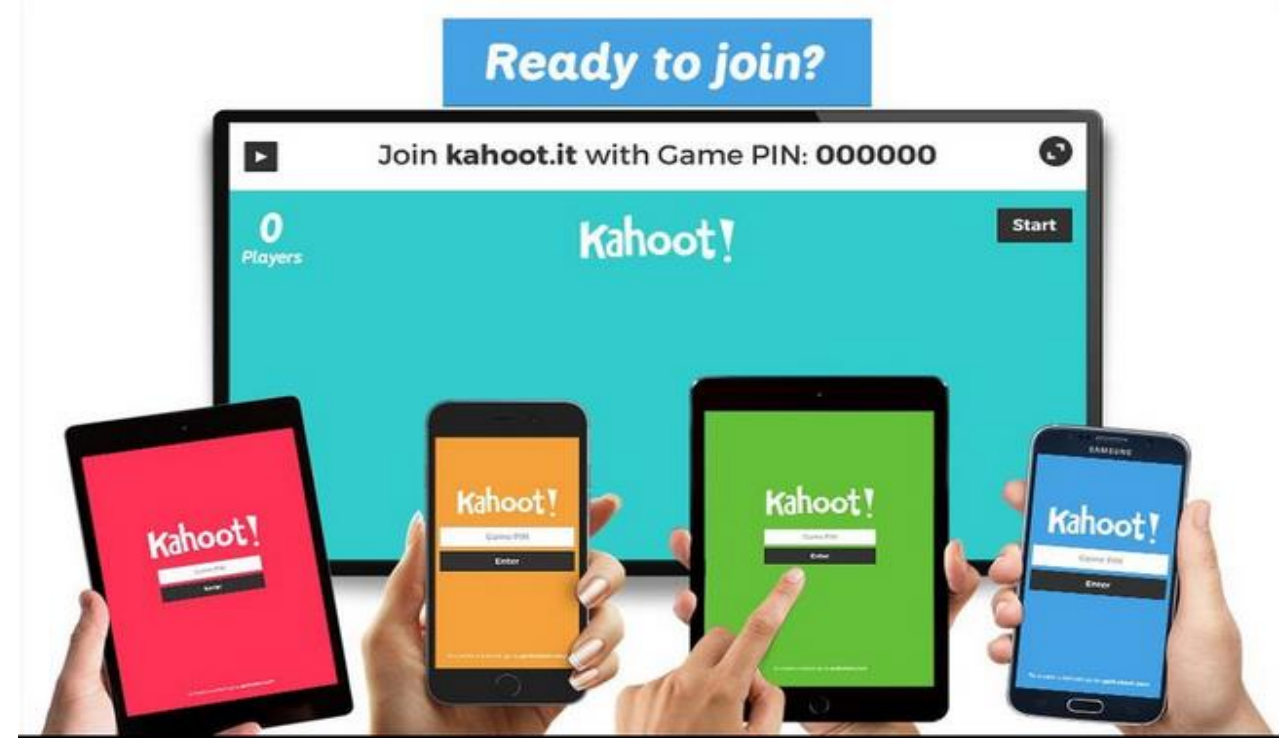

Fonte: https://guides.dtwd.wa.gov.au/c.php?g=171196\&p=5670822 
Após acessar a plataforma pelo smartphone, cada grupo escolheu um nickname (nome fictício) para o grupo. A cada pergunta projetada na tela, havia quatro respostas possíveis, sendo apenas uma verdadeira. Cada resposta foi apresentada dentro de um quadro contendo uma cor e um símbolo. Nos smartphones, foram mostrados apenas os símbolos e as cores. A cada pergunta, foram concedidos 40 segundos para a discussão dos grupos. Enquanto os alunos discutiam, a própria plataforma reproduzia uma música. Além disso, a orientação aos alunos era que procurassem interagir o máximo que pudessem usando a língua inglesa. Foi utilizado um quiz já disponível na plataforma, o qual abordava trinta e duas questões com foco em jobs and occupations. As questões exploravam imagens e diagramas, bem como elementos lexicais, gramaticais e pragmáticos, tais como: a) o uso adequado de artigos; b) a utilização de palavras interrogativas para obter informações específicas: c) pronomes sujeitos e objetos; e d) as situações de uso do vocabulário relativas a profissões. Podemos observar na figura 2, a seguir, que a questão ilustrada explora não só vocabulário voltado para profissão, mas também o uso adequado do artigo indefinido em inglês.

Figura 2- Questão 8 do quiz sobre Jobs and Occupations

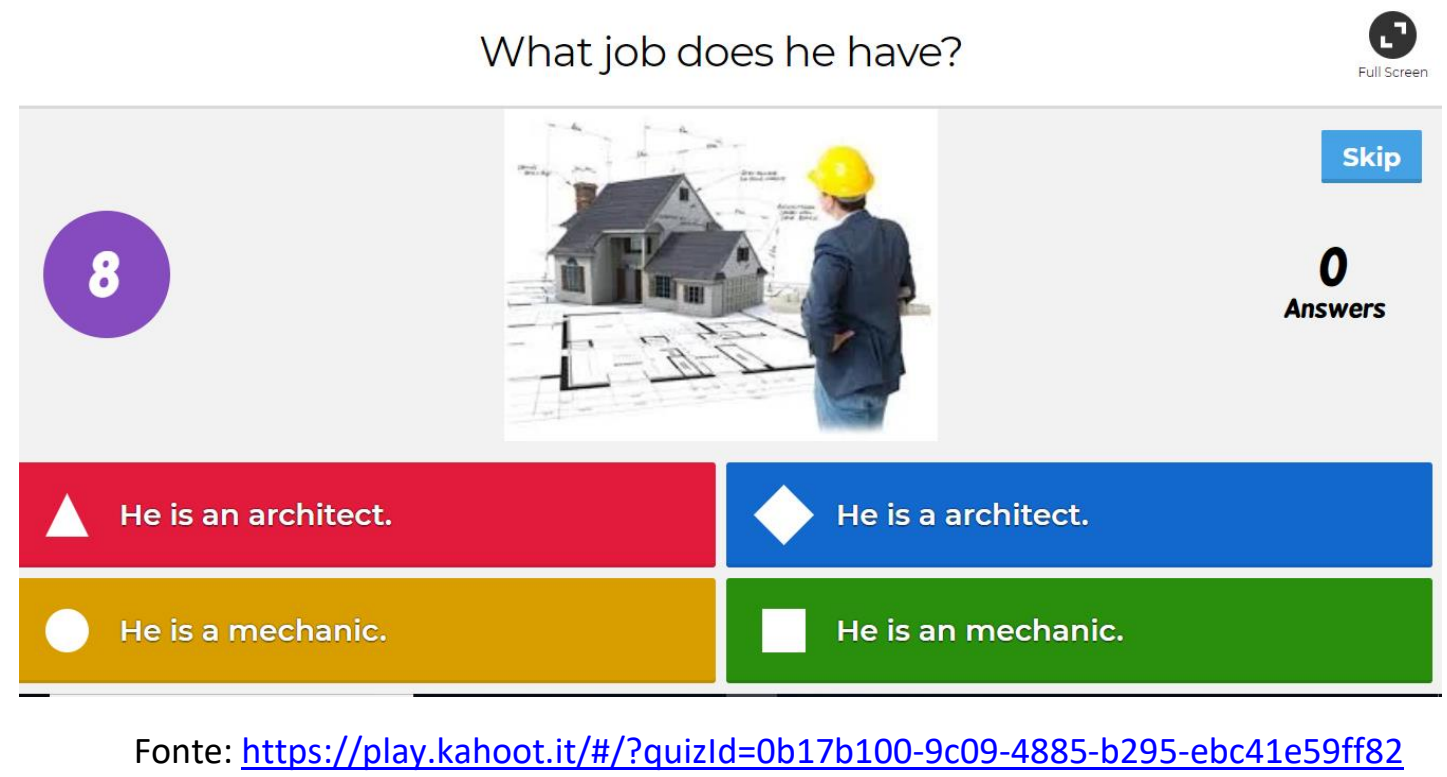

Finalmente, na quarta etapa, foi proposta a aplicação (ou prática transformada) que está relacionada à capacidade do aprendiz no que tange à aplicação de novos conhecimentos e habilidades para se engajar em comunicações multimodais de maneiras criativas, levando em conta seus interesses, experiências e aspirações, transformando, assim, sua realidade (COPE; KALANTZIS, 2009). Desse modo, os aprendizes deveriam gravar um vídeo, por meio de seus smartphones, com o intuito de fazer uma autoapresentação (self-intro video), na qual eles teriam que utilizar os conhecimentos linguísticos construídos ao longo do semestre e, sobretudo, falar sobre suas preferências, profissões e aspirações. 


\section{Percepções dos alunos em relação ao uso do Kahoot na aprendizagem de inglês}

Com a intenção de investigar os aspectos positivos e negativos da atividade com o uso do Kahoot, apresentada neste estudo, solicitamos aos participantes que escrevessem uma narrativa de aprendizagem, relatando a experiência durante a realização do jogo proporcionado por tal plataforma. Adicionalmente, foram feitas algumas perguntas, no questionário aplicado após a experiência, com o objetivo de registrar as impressões dos alunos em relação à contribuição do uso dessa ferramenta para a aprendizagem de língua inglesa. Para ilustrar as análises, utilizamos excertos das narrativas escritas pelos aprendizes e suas respostas ao questionário. Os participantes escolheram seus pseudônimos, com vistas à preservação de suas identidades.

A partir das respostas do questionário, podemos inferir que nenhum dos alunos havia tido experiências com o uso da plataforma Kahoot anteriormente a essa atividade. De um modo geral, os aprendizes avaliaram essa experiência como motivadora, envolvente, divertida e autêntica.

As percepções dos participantes apontaram para os efeitos positivos advindos da utilização da ferramenta Kahoot na aprendizagem de língua inglesa, sob o viés dos multiletramentos integrado à aprendizagem colaborativa. Através dos dados provenientes das narrativas e do questionário, podemos observar que as percepções dos alunos revelam que a atividade envolvendo tal recurso pode contribuir para: promover práticas de leitura de textos multimodais; estimular o fornecimento de scaffolding entre os aprendizes de inglês; promover a superação da timidez e o engajamento em diálogos colaborativos; monitorar a própria aprendizagem; incentivar e envolver os alunos na aprendizagem de inglês; e fornecer feedback corretivo de formas variadas, como é ilustrado a seguir.

\section{a) Promover práticas de leitura de textos multimodais}

Conforme discutido anteriormente, a plataforma Kahoot veicula diferentes linguagens e textos multimodais, visto que é possível criar quizzes de múltipla escolha integrados a vídeos, imagens, diagramas etc. (LICORISH et al., 2017; MISSAGIA; GERRA, 2018; VALLIM; GOMES; FISCHER, 2017). Dessa forma, tal ferramenta promove a construção de sentidos através da interpretação de textos multimodais (PAESANI; ALLEN; DUPUY, 2016). No excerto 1 , podemos ver a percepção do participante Civínio no que se refere ao caráter multimodal/multissemiótico do quiz disponibilizado pela plataforma em estudo, uma vez que ele menciona a combinação de texto escrito, som, imagens ou digramas, fato que, 
segundo ele, contribuiu para a construção de sentidos do texto apresentado. Observemos seu depoimento:

[1]

Toda a turma participou, o que já é um detalhe importante. O jogo de perguntas e acertos tinha um tempo cronometrado para receber as respostas dos grupos e aquele que marcasse a opção correta levaria mais pontos e ficaria à frente no ranking. Cada pergunta de múltipla escolha possuía imagens ou diagramas, o que facilitava a cognição e assimilação do que aparecia na tela. Um ambiente descontraído e competitivo estimulava a atenção para marcarmos a alternativa correta e vencermos.

(Civínio - narrativa de aprendizagem)

b) Estimular o fornecimento de scaffolding entre os aprendizes de inglês

Foi possível observar, por meio das narrativas de aprendizagem, que a plataforma proporcionou uma situação de colaboração, que contribuiu para aprendizagem dos interagentes de modo significativo. É interessante notar, no excerto 2, que a interação promovida pela plataforma estimulou o fornecimento coletivo de scaffolding, visto que a participante Alice destaca a ajuda fornecida não só por colegas mais competentes, mas também por colegas menos experientes na língua-alvo. Tal fato corrobora a afirmação de Figueiredo (2006) de que, por meio da interação, todos aprendem, sejam menos experientes ou não. Adicionalmente, conforme argumenta Wertsch (1979, apud DONATO, 1994), em um trabalho em grupo, a ajuda não precisa necessariamente vir de um par mais competente, isto é, cada membro pode contribuir para a execução de um objetivo em comum a partir de suas habilidades específicas e que, por vezes, podem ser complementares. Nesse sentido, o indício de que houve o fornecimento de scaffolding coletivo (DONATO, 1994) pode ser confirmado nos excertos 2 e 3 , já que a participante Alice, no excerto 2, salienta o fato de que cada membro do grupo, durante o jogo, utilizou sua habilidade para ajudar uns aos outros a alcançar bons resultados. Já no excerto 3, o participante Peter ressalta que, enquanto um participante pesquisava a resposta certa, o outro selecionava a opção correta. Tais aspectos podem ser verificados nos excertos 2 e 3 :

[2]

O jogo trabalha agilidade e instiga o conhecimento do aluno. Os grupos precisavam interagir entre si porque até mesmo aqueles alunos que possuíam um nível avançado na língua precisaram da ajuda dos colegas, pois as habilidades de todos se complementavam para que fosse possível conseguir um bom resultado.

(Alice - narrativa de aprendizagem) 
[3]

Com a plataforma é possível criar uma interação com os colegas de turma afim de conseguir o melhor resultado e pontuação. Há aquisição de novos vocabulários e enquanto um aluno pesquisa o outro seleciona. Por isso, essa interação garante um aprendizado mais interativo e na minha opinião bem mais eficaz.

(Peter - questionário, pergunta 3)

\section{c) Promover a superação da timidez e o engajamento em diálogos colaborativos}

De acordo com Wells (1999), o caráter afetivo na interação entre os alunos constitui um aspecto importante na promoção de uma aprendizagem colaborativa. Nessa direção, conforme discutimos na primeira seção, Scarcella e Oxford (1992) ressaltam alguns fatores afetivos que podem influenciar no processo de aprendizagem. Ainda nessa linha, a timidez ou a falta de apoio mútuo entre os interagentes, dentre outros fatores afetivos, podem impedir ou prejudicar o processo interacional na língua-alvo (LAGO, 2011; SCARCELLA; OXFORD, 1992; WELLS, 1999). Desse modo, o professor deve lançar mão dos diferentes tipos de assistência para tornar a aprendizagem da língua mais significativa para o aprendiz, seja por meio de recursos didáticos, seja através da promoção de situações nas quais o aluno tenha a oportunidade de receber assistência dos próprios colegas e produzir na língua inglesa (HALL, 2001; SCARCELLA; OXFORD, 1992; SWAIN, 1995). Partindo desses aspectos, podemos perceber, no excerto 4, que a ferramenta Kahoot pode consistir em um tipo de assistência, nesse contexto, visto que proporcionou uma superação do desconforto que os aprendizes sentiam durante situações de interação, dando lugar a um diálogo colaborativo que contribuiu para o avanço na aprendizagem da língua-alvo. Observemos o excerto 4 para verificar os indícios dos aspectos supracitados:

[4]

A primeira impressão sobre a utilização da plataforma foi a interação da turma. Temos um perfil de pessoas tímidas na conversação e na interação, na hora de propor dinâmicas e exercícios de fala na 2a língua. Com a plataforma, de imediato as pessoas começaram a interagir. A competitividade saudável deu lugar ao trabalho em grupo e aquisição de vários outros vocabulários em inglês, reforçando a matéria dada em sala, com a interatividade da turma.

(Peter - narrativa de aprendizagem)

\section{d) Monitorar a própria aprendizagem}

O monitoramento da própria aprendizagem consiste em uma estratégia metacognitiva que, por sua vez, refere-se a uma ação autônoma fundamental no processo de aprendizagem. Ela ocorre quando o aprendiz consegue reconhecer suas dificuldades e 
busca desenvolver estratégias para a superação de obstáculos eventualmente encontrados no processo de aprender (BENSON, 1997; DICKINSON, 1994; FIGUEIREDO, 2006).

Nos excertos 5 e 6, é possível observar a tomada de consciência das dificuldades por Alice e Harry, respectivamente. Ao considerar que a plataforma Kahoot promoveu a colaboração entre os participantes, como vimos nos excertos 2, 3 e 4, podemos constatar que o tipo de interação proporcionado pelo jogo favoreceu a ativação da estratégia de monitoramento da aprendizagem pelos alunos. Tal fato pode ser evidenciado nos seguintes excertos:

[5]

Durante a realização do jogo, percebi algumas dificuldades que eu tinha e que precisava melhorar. Também aprendi algumas palavras novas. Achei uma aula incrível, pois a plataforma torna o aprendizado algo divertido e interativo. Poderia passar horas jogando e não me cansaria.

(Alice - narrativa de aprendizagem)

[6]

O jogo mostrou algumas estruturas que eu ainda tinha dúvidas e eu ficava tentando entender no contexto. Mas quando eu não conseguia, eu perguntava para os colegas sobre essas dúvidas e eles me ajudavam. Por isso, achei bem produtivo.

(Harry - narrativa de aprendizagem)

e) Incentivar e envolver os aprendizes na aprendizagem de inglês

Outro aspecto que merece atenção tem a ver com o fato de que a plataforma se mostrou eficiente na promoção de uma aprendizagem mais significativa em língua inglesa. Em primeiro lugar, porque envolveu os alunos na situação de aprendizagem, despertando a curiosidade e o interesse, como pode ser observado nos excertos 7, 8 e 9. Em segundo lugar, porque promoveu a participação ativa dos aprendizes na construção do próprio conhecimento sem a interferência direta do professor. Tais considerações corroboram os estudos de Licorish et al. (2017) no tocante ao uso do Kahoot como um recurso didático envolvente e motivador na aprendizagem de línguas. A título de exemplo, vejamos os excertos seguintes:

[7]

A plataforma é um instrumento interessante no aprendizado, pois envolve os alunos e estabelece uma interação entre eles fazendo-os compartilhar conhecimento. Torna o aprendizado da língua algo divertido e prazeroso.

(Alice - questionário, pergunta 3) 
[8]

Minhas impressões são boas [sobre o uso da plataforma], o aprendizado se torna mais divertido e prende a atenção dos alunos.

(Diana - questionário, pergunta 3)

[9]

Eu gostei muito de utilizar o site [Kahoot], por ser criativo e divertido. A necessidade do raciocínio rápido para responder às questões prende a atenção, aguça a curiosidade e desperta o interesse.

(DD - narrativa de aprendizagem)

f) Fornecer feedback corretivo de formas variadas

Figueiredo $(2005,2015)$ afirma que a literatura nos mostra que corrigir é um processo extremamente complexo, pois há diferentes formas de abordar o erro, bem como diversos modos de correção. Nesta pesquisa, os dados mostram que a atividade com o uso do Kahoot proporcionou três formas distintas de feedback: 1) feedback direto, fornecido pela própria ferramenta, uma vez que o jogo apresentava a resposta correta após o tempo concedido para a marcação da resposta, como pode ser observado no excerto $10 ; 2$ ) feedback fornecido pelos próprios interagentes, já que os membros dentro do próprio grupo e até de grupos diferentes explicavam por que algumas respostas eram consideradas corretas e/ou erradas, conforme podemos ver no excerto 11; e, finalmente, 3) o feedback concedido pelo professor ao final do jogo na forma de esclarecimento de dúvidas, como podemos verificar no excerto 12 .

[10]

Eficiente e dinâmico [o uso do Kahoot]. A plataforma foi explorada com um game descontraído e competitivo. Não me lembro do que mais ofereciam, mas posso dizer que as ferramentas que usamos foram bem satisfatórias e envolventes. O que mais gostei foi de receber as respostas corretas no fim de cada partida. Assim quando errávamos ainda poderíamos aprender a palavra certa.

(Civínio - questionário, pergunta 3)

[11]

Achei legal quando o meu grupo não sabia por que a resposta que a gente tinha marcado estava errada e a gente ficava perguntando um ao outro. Mesmo competindo o outro grupo que tinha marcado a resposta certa explicou para gente, porque ela estava errada. Então, a interação e a ajuda não ficaram só dentro de um mesmo grupo, todos interagiram e se ajudaram, e assim, a gente conseguiu aprender mais.

(Harry - narrativa de aprendizagem) 
[12]

A mediação aluno-professor não foi incisiva durante o jogo, pois não havia muito a ser feito por ele sem que desse respostas do game. Entretanto, ao fim do jogo, algumas dúvidas foram esclarecidas para toda a sala.

(Civínio - narrativa de aprendizagem)

Ainda sobre o excerto 11, é interessante notar que os aprendizes solicitavam esclarecimentos sobre seus erros e, por conseguinte, recebiam feedback não só dos membros de seus próprios grupos, mas também, de membros de outros grupos. Figueiredo (2005, p. 71) expõe que a "[...] correção realizada com os colegas está fundamentada na noção vygostskiana e nos princípios da aprendizagem colaborativa", visto que, por meio da interação, os alunos ajudam uns aos outros a melhorar os textos por eles escritos. Sob essa ótica, podemos observar que o feedback evidenciado no excerto 11 se trata de uma correção colaborativa, isto é, uma correção realizada a partir da negociação de papéis, significados e do compartilhamento de saberes (DONATO, 1994; FIGUEIREDO, 2005; LIMA; COSTA, 2007).

Por fim, embora a maioria dos participantes não tenha destacado aspectos negativos a respeito do uso da plataforma digital na aprendizagem de línguas, a participante DD apontou a falta de conhecimento em língua inglesa como um aspecto negativo que, segundo ela, pode desmotivar o aprendiz durante a participação em uma atividade com esse recurso. Tal fato pode ser observado no excerto 13:

[13]

É possível que a pessoa que esteja nos primeiros passos do estudo do Inglês fique desmotivada com a proposta do Kahoot. Mas para quem tem um conhecimento básico ou razoável da língua, ele pode ser uma excelente ferramenta de estudo.

(DD - narrativa de aprendizagem)

Apesar disso, como vimos nos excertos 1, 2, 3, 4, 5, 6 e 10, a plataforma em questão proporcionou um ambiente colaborativo, no qual os interagentes coconstruíram e negociaram sentidos a partir de textos multimodais, de forma a contribuir para a aprendizagem uns dos outros. Portanto, um aprendiz que estivesse na situação descrita pela participante DD, no excerto 13, poderia ainda contar com o fornecimento de scaffolding pelos colegas e se engajar na atividade proposta (DONATO; MCCORMICK, 1994; FIGUEIREDO, 2006, 2019; LANTOLF; APPEL, 1994). 


\section{Tecendo algumas considerações finais}

Este estudo buscou investigar uma proposta de atividade voltada para aprendizes de Língua Inglesa I do Curso de Letras-Inglês, de uma instituição privada, a partir de um jogo disponível na plataforma Kahoot, numa perspectiva que alia a pedagogia dos multiletramentos à aprendizagem colaborativa. Seguimos, na condução do estudo, a tendência atual de incorporação das novas tecnologias à sala de aula de línguas estrangeiras. Conforme advoga Karsenti (2019), a abertura da sala a essas tecnologias se faz altamente necessária, e educadores podem e devem fazer amplo uso delas, visto que têm "[...] penetrado todas as esferas educacionais, na forma de leitores para e-book, navegadores, aplicativos educacionais e plataformas de aprendizagem, para nomear apenas algumas."13

A plataforma Kahoot foi eleita por duas razões: a) porque veicula diferentes linguagens e textos multimodais, uma vez que é possível criar quizzes de múltipla escolha integrados a vídeos, imagens, sons, diagramas etc.; e b) porque consiste em uma plataforma digital on-line gratuita que promove a interação entre os usuários a partir da opção Team mode, de forma a contribuir com a negociação de significados e compartilhamento de saberes entre os interagentes (MISSAGIA; GUERRA, 2018; VALLIM; GOMES; FISCHER, 2017).

A análise dos dados nos permite afirmar que a proposta da atividade com a utilização do Kahoot evidenciou aspectos que caracterizam os princípios das práticas de multiletramentos, visto que promoveu a reflexão dos aprendizes, no sentido de estabelecer relações entre os significados emergentes de textos multimodais de maneira colaborativa (COPE; KALANTZIS, 2009).

As percepções dos participantes apontam para os benefícios provenientes da utilização da ferramenta em foco na aprendizagem de inglês, neste estudo, sob o viés dos multiletramentos integrados à aprendizagem colaborativa. Dentre os aspectos positivos, podemos citar os seguintes: a) a promoção de práticas de leitura de textos multimodais; b) o estímulo ao fornecimento de scaffolding entre os alunos de inglês; c) a promoção do diálogo colaborativo na língua-alvo; d) o monitoramento da própria aprendizagem; e) o incentivo e envolvimento dos aprendizes na aprendizagem de língua inglesa; e, por fim, f) o fornecimento de feedback corretivo de formas variadas. Como aspecto negativo, foi mencionado por uma participante que, para jogar no Kahoot, o aprendiz precisaria ter algum conhecimento de língua inglesa.

Pillay (2010, p. 771) defende que "os professores de universidades deveriam não apenas abraçar o multiletramento para o ensino e a aprendizagem, mas aceitar, incorporar e

\footnotetext{
${ }^{13}$ Original: "[...] penetrated all the education spheres, in the form of intelligent books, web browsers, education apps, and learning platforms, to name a few."
} 
reafirmar os muitos letramentos que os alunos trazem consigo para a sala de aula. ${ }^{14} \mathrm{~A}$ partir do exposto, podemos afirmar que a ação pedagógica, a partir da ferramenta Kahoot, numa perspectiva dos multiletramentos atrelada à aprendizagem colaborativa - na universidade, em escolas de idiomas ou até mesmo nas regulares (privadas ou públicas) - consiste em uma prática envolvente, motivadora, colaborativa e multimodal e, portanto, eficaz para a educação linguística no contexto da contemporaneidade.

\section{Referências}

AGUILAR, M. J. C. Dealing with intercultural communicative competence in the foreign language classroom. In: SOLER, E. A.; SAFONT JORDA, M. P. (Org.). Intercultural language learning and language use. Dordrecht, The Netherlands: Springer, 2007. p. 58-78.

BENSON, P. The philosophy and politics of learner autonomy. In: BENSON, P.; VOLLER, P. (Org.). Autonomy and independence in language learning. London: Longman, 1997. p. 18-34.

COPE, B.; KALANTZIS, M. Multiliteracies: Literacy learning and the design of social futures. London: Routledge, 2000.

COPE, B.; KALANTZIS, M. Multiliteracies: New literacies, new learning. Pedagogies: An International Journal, Nanyang Walk, v. 4, n. 3, p. 164-195, 2009. https://doi.org/10.1080/15544800903076044

DIAS, R. WebQuests: tecnologias, multiletramentos e a formação do professor de inglês para a era do ciberespaço. Revista Brasileira de Linguística Aplicada, Belo Horizonte, v. 12, n. 1, p. 861-881, 2012. https://doi.org/10.1590/S1984-63982012000400010

DICKINSON, L. Learner autonomy: what, why and how? In: LEFFA, V. J. (Ed.). Autonomy in Language Learning. Porto Alegre: UFRGS, 1994. p. 2-12.

DONATO, R. Collective scaffolding in second language learning. In: LANTOLF, J. P.; APPEL, G. (Eds.). Vygotskian approaches to second language learning. Norwood, N. J.: Ablex Publishing Company, 1994. p. 33-56.

DONATO, R.; MCCORMICK, D. A. A sociocultural perspective on language learning Strategies: The role of mediation. The Modem Language Journal, v. 78, n. 4, p. 453-464, 1994. https://doi.org/10.1111/j.1540-4781.1994.tb02063.x

ELLIS, R. Second language acquisition. Oxford University Press, 2009.

FIGUEIREDO, F. J. Q. Semeando a interação: a revisão dialógica de textos escritos em língua estrangeira. Goiânia: Ed. UFG, 2005.

14 Original: "lecturers at institutions of higher education not just embrace multiliteracy for teaching and learning, but accept, incorporate and affirm the many literacies that students bring with them to the lecture room." 
FIGUEIREDO, F. J. Q. A aprendizagem colaborativa de línguas: algumas considerações conceituais e terminológicas. In: FIGUEIREDO, F. J. Q. (Org.). A aprendizagem colaborativa de línguas. Goiânia: Ed. da UFG, 2006. p. 11-45.

FIGUEIREDO, F. J. Q. Aprendendo com os erros: uma perspectiva comunicativa de ensino de línguas. 3. ed. Goiânia: Editora UFG, 2015.

FIGUEIREDO, F. J. Q. Vygotsky: a interação no ensino/aprendizagem de línguas. São Paulo: Parábola, 2019.

FREEMAN, D.; JOHNSON, K. E. Reconceptualizing the knowledge-base of language teacher education. TESOL Quartely, v. 32, n. 3, p. 397-417, 1998. https://doi.org/10.2307/3588114

HALL, J. K. Classroom interaction and language learning. Ilha do Desterro, Florianópolis, n. 41, p. 17-39, 2001.

KARSENTI, T. Artificial intelligence in education: the urgent need to prepare teachers for tomorrow's schools. Formation et profession, v. 27, n. 1, p. 105-111, 2019. https://doi.org/10.18162/fp.2019.a166

KESSLER, G; HUBBARD, P. Language teacher education and technology. In: CHAPELLE, C. A; SAURO, S. The handbook of technology and second language teaching and learning. Nova Jersey: John Wiley \& Sons, 2017. https://doi.org/10.1002/9781118914069.ch19

KRESS, G. Multimodality: A social semiotic approach to contemporary communication. London: Routledge, 2010. https://doi.org/10.4324/9780203970034

LAGO, N. A. Um olhar pelos recônditos: fatores afetivos e aprendizagem de línguas estrangeiras. In: CRUZ, N. C.; PINHEIRO-MARIZ, J. (Org.). Ensino de línguas estrangeiras: contribuições teóricas e de pesquisa. Campina Grande: EDUFCG, 2011. p. 11-36.

LANKSHEAR, C.; SNYDER, I.; GREEN, B. Teachers and technoliteracy: Managing literacy, technology and learning in schools. St. Leonards: Allen \& Unwin, 2000.

LANTOLF, J. P.; APPEL, G. Theoretical framework: An introduction to Vygotskian approaches to second language research. In: LANTOLF, J. P.; APPEL, G. (Org.). Vygotskian approaches to second language research. New Jersey: Ablex Publishing Corporation, 1994. p. 1-32.

LEMKE, J. L. Letramento metamidiático: transformando significados e mídias. Trabalhos em Linguística Aplicada, Campinas, v. 2, n. 49, p. 455-479, 2010. https://doi.org/10.1590/S010318132010000200009

LENHARO, R. I.; CRISTOVÃO, V. L. Multiletramentos no ensino de língua inglesa em um contexto de vulnerabilidade social. Revista Linguagem \& Ensino, Pelotas, v. 21, n. 1, p. 367402, 2018.

LICORISH, S. A. et al. "Go Kahoot": Enriching classroom engagement, motivation and learning experience with games. In: Proceedings of the International Conference on Computers in Education, 25, 2017. Anais... New Zealand: Asia Pacific Society for Computers in Education, 2017. p. 755-764.

LIMA, M. D. S.; COSTA, P. S. C. A tarefa colaborativa como estímulo a negociação, correção e aprendizagem de línguas. In: Congresso Latino Americano sobre Formação de Professores de 
Línguas (CLAFPL), 1, 2007. Anais...Porto Alegre: Pós-graduação em Letras e Linguística da UFSC, 2007. p. 598-606.

MISSAGIA, E. V.; GUERRA, D. C. S. O uso da plataforma Kahoot como complemento do gênero Exposição Oral. In: Simpósio Ibero-Americano de Tecnologias Educacionais, 2, 2018. Anais... Araranguá: Centro de Ciências, Tecnologias e Saúde da UFSC - Campus Araranguá, 2018. p. 383-391.

NEW LONDON GROUP. A pedagogy of multiliteracies: Designing social futures. Harvard $\begin{array}{lllllll}\text { Educational Review, } & \text { v. 66, n. } 1, \quad \text { p. } & 60-92, & \end{array}$ https://doi.org/10.17763/haer.66.1.17370n67v22j160u

NÓVOA, A. Nota de abertura. In: BARBOSA, M. V. et al. (Org.). A boniteza de ensinar e a identidade do professor na contemporaneidade. Campinas: Mercado de Letras, 2015. p. 1116.

NUNAN, D. Research methods in language teaching. Cambridge: Cambridge University Press, 1992.

PAESANI, K.; ALLEN, H. W.; DUPUY, B. A multiliteracies framework for collegiate foreign language teaching. Upper Saddle River, NJ: Pearson, 2016.

PAIVA, V. L. M. O. A WWW e o ensino de inglês. Revista Brasileira de Linguística Aplicada, v. 1, n. 1, p. 93 -116, 2001. https://doi.org/10.1590/S1984-63982001000100006

PÉREZ SERRANO, G. Técnicas de investigación en educación social: perspectiva etnográfica. In: PÉREZ SERRANO, G. Investigación cualitativa. Retos e interrogantes: II. Técnicas y Análisis de Datos. Madrid: La Muralla, 1998. p. 13-70.

PILLAY, A. Embracing multiliteracy for teaching and learning in higher education. South African Journal of Higher Education, v. 24, n. 5, p. 771-781, 2010.

ROJO, R. H. R. Letramentos múltiplos, escola e inclusão social. São Paulo: Parábola, 2009.

ROJO, R. H. R. Pedagogia dos multiletramentos: diversidade cultural e de linguagens na escola. In: ROJO, R. H. R.; MOURA, E. (Org.). Multiletramentos na escola. São Paulo: Parábola Editorial, 2012. p. 11-32.

SCARCELLA, R. C.; OXFORD, R. L. The tapestry of language learning. Boston: Heinle \& Heinle Publishers, 1992.

SWAIN, M. Three functions of output in second language learning. In: COOK, G.; SEIDLHOFER, B. (Ed.). Principle \& practice in applied linguistics. Oxford: Oxford University Press, 1995. p. 125-144.

SWAIN, M. The output hypothesis and beyond: Mediating acquisition through collaborative dialogue. In: LANTOLF, J. (Ed.). Sociocultural theory and second language learning. Oxford: Oxford University Press, 2000. p. 97-114.

VALLIM, M. A. G.; GOMES, S. T.; FISCHER, C. R. Vivenciando inglês com Kahoot. The ESPecialist: Descrição, Ensino e Aprendizagem, São Paulo, v. 38, n. 1, p. 1-18, jan-jul. 2017. https://doi.org/10.23925/2318-7115.2017v38i1a11 
VURDIEN, R. Videoconferencing: developing students' communicative competence. Journal of Foreign Language Education and Technology, v. 4, n. 2, p. 269-298, 2019.

VYGOTSKY, L. S. A formação social da mente: o desenvolvimento dos processos psicológicos superiores. São Paulo: Martins Fontes, 1998.

WARNER, C.; DUPUY, B. C. Moving toward multiliteracies in foreign language teaching: past and present perspectives... and beyond. Foreign Language Annals - American Council on the Teaching of Foreign Languages, 2018. p. 1-13. https://doi.org/10.1111/flan.12316

WARNER, C.; RICHARDSON, D. Beyond participation: symbolic struggles with(in) digital social media in the L2 classroom. In: DUBREIL, S.; THORNE, S. (Ed.). Engaging the world: social pedagogies and language learning. Boston: Cengage, 2017. p. 199-226.

WARSCHAUER, M. Computer assisted language learning: An introduction. In: FOTOS, S. (Ed.). Multimedia language teaching. Tokyo: Logos International, 1996. p. 3-20.

WELLS, G. Dialogic inquiry: Towards a sociocultural practice and theory of education. Cambridge: Cambridge University Press, 1999. https://doi.org/10.1017/CBO9780511605895

WOOD, D.; BRUNER, J. S.; ROSS, G. The role of tutoring in problem solving. Journal of Child Psychology and Psychiatry, v. 17, p. 89-100, 1976. https://doi.org/10.1111/i.14697610.1976.tb00381.x

\section{Apêndice A}

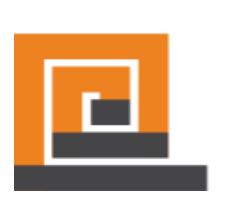

\section{PROGRAMA DE PÓȘ-GRADUAÇÃO LETRAS E LINGUISTICA \\ FACULDADE DE LETRAS - UFG}

Pesquisadores responsáveis:

Caro aluno,

Peço sua colaboração para escrever essa narrativa, que é extremamente importante para a pesquisa que está sendo realizada e ajudará a observar as contribuições dos recursos disponíveis pelas TIDICS (Novas Tecnologias Digitais de Informação e Comunicação) para a aprendizagem de língua inglesa. Informações pessoais como nome, turma e instituição de ensino não serão divulgadas, com o objetivo de preservar o anonimato dos participantes.

Pseudônimo:

Escreva uma breve narrativa relatando sua experiência durante a realização do jogo proporcionado pela plataforma Kahoot. Procure comentar sobre como, o quê e o porquê você conseguiu aprender a partir dessa experiência. 


\section{Apêndice B

Pesquisadores responsáveis:

Caro aluno,

Peço sua colaboração para responder este questionário, que é extremamente importante para a pesquisa que está sendo realizada e ajudará a observar as contribuições dos recursos disponíveis pelas TIDICS (Novas Tecnologias Digitais de Informação e Comunicação) para a aprendizagem de língua inglesa. Informações pessoais como nome, turma e instituição de ensino não serão divulgadas, com o objetivo de preservar o anonimato dos participantes.

Pseudônimo:

1. Anteriormente à disciplina "Língua Inglesa I", você já havia tido alguma experiência com a utilização da internet ou recursos digitais para a aprendizagem de língua inglesa? Em caso positivo, comente, por favor. 
Experiências de aprendizes de inglês da educação superior com o Kahoot
Fernanda Franco Tiraboschi Laryssa Paulino de Queiroz Sousa Francisco José Quaresma de Figueiredo Neuda Alves do Lago

2. Você já teve alguma experiência com o uso de websites para a realização de atividades em grupo em sala de aula?

3. Quais os aspectos positivos e negativos relacionados ao uso da ferramenta Kahoot na aprendizagem de língua inglesa?

Recebido em: 09/06 /2019

Aceito em: 22/10/2019 